\title{
Use of a wind profiler in a planetary boundary layer experiment
}

D. Ruffieux

SMI/MeteoSwiss, Les Invuardes, CH-1530 Payerne, Switzerland
The wind profiler is an active ground-based remote sensing system which records automatically wind profiles in the planetary boundary layer. Wind speed and direction as well as information on the mixing height are of first importance for air pollution studies. Preliminary analysis of wind profiler data from the PIPAPO Experiment illustrates the potential of such systems to help describing tropospheric ozone transport from the Milano region toward the Alps.

\section{Introduction}

Knowledge of the meteorological parameters is a key factor for planetary boundary layer (PBL) air pollution studies. The transport of the pollutants, from the emission to the deposition location (where they are measured), depends mainly on the wind regimes, but also on others parameters like atmospheric stability or precipitation. The wind profiler is a powerful tool to measure profiles of wind speed and wind direction in the PBL with a good temporal (few minutes) and vertical resolution $(60 \mathrm{~m})$ [1]. These data can be used directly in the analysis of special events or as assimilation products for numerical modeling. Supplementary information on the vertical structure of the atmosphere can also be determined [2].

\section{Principle of operation}

The low-tropospheric wind profiler is a Doppler radar running at $1290 \mathrm{MHz}$. An electromagnetic pulse is emitted toward the zenith and two $15^{\circ}$-tilted directions (north and west, for example). At that frequency, the return signal intensity depends mainly on humidity and temperature gradients in the atmosphere. This very low return signal is recorded and analyzed in real time by the system. A succession of coherent average and noise filtering steps are followed by a Fast Fourier Transform. The frequency spectrum obtained for each gate (typically layers of 60 to $400 \mathrm{~m}$ thickness, depending on the setup) can be characterized by his four moments: noise level, signal power, spectral width and Doppler shift. By combining the Doppler shift of the three beams, mean wind speed and wind direction can be 
estimated for each considered gate. During the PIPAPO Experiment (see below), even with a low power emission (500 Watts - peak power), it was possible to estimate winds from about $100 \mathrm{~m}$ agl to up to $3000 \mathrm{~m}$ agl with a vertical resolution of $200 \mathrm{~m}$ during more than $70 \%$ of the time.

\section{The wind profiler and the LOOP Experiment}

In the frame of the European program EUROTRAC, in connection with the project LOOP (Limitation $\underline{\text { Of }}$ Oxydant Production), an intensive experiment was organized in the Po region (northern Italy). The PIPAPO Experiment (Pianura

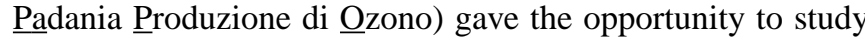
transport of ozone from the Milano area toward the southern Switzerland [3]. During PIPAPO, the wind profiler was located in the center of the region of interest, at Seregno, and operated continuously from 12 May 1998 to 8 June
1998. Hourly profiles of wind speed and direction were calculated and displayed in real time. As examples, wind profiler data from two high ozone days are described in the next paragraphs.

The $1^{\text {st }}$ June 1998 was characterized by a high surface pressure over southern Europe and synoptic winds blowing from the west. This main flow was perturbed by local and regional effects as shown in figure 1. At Seregno, below the westerlies, a southerly regime developed from early morning to late afternoon, while the nighttime registered periods of weak and variable winds. Various layers can be detected on the time series of wind profiles. The dashed line in figure 1 defines a boundary characterized by a strong wind shear between the synoptic westerly flow and the regional more southerly wind blowing just below it. It might be caused by differential thermal heating between the Po Basin and the Alps. Note a still unexplained "region" of northwesterly winds blowing early morning (area delimited by the dotted line).

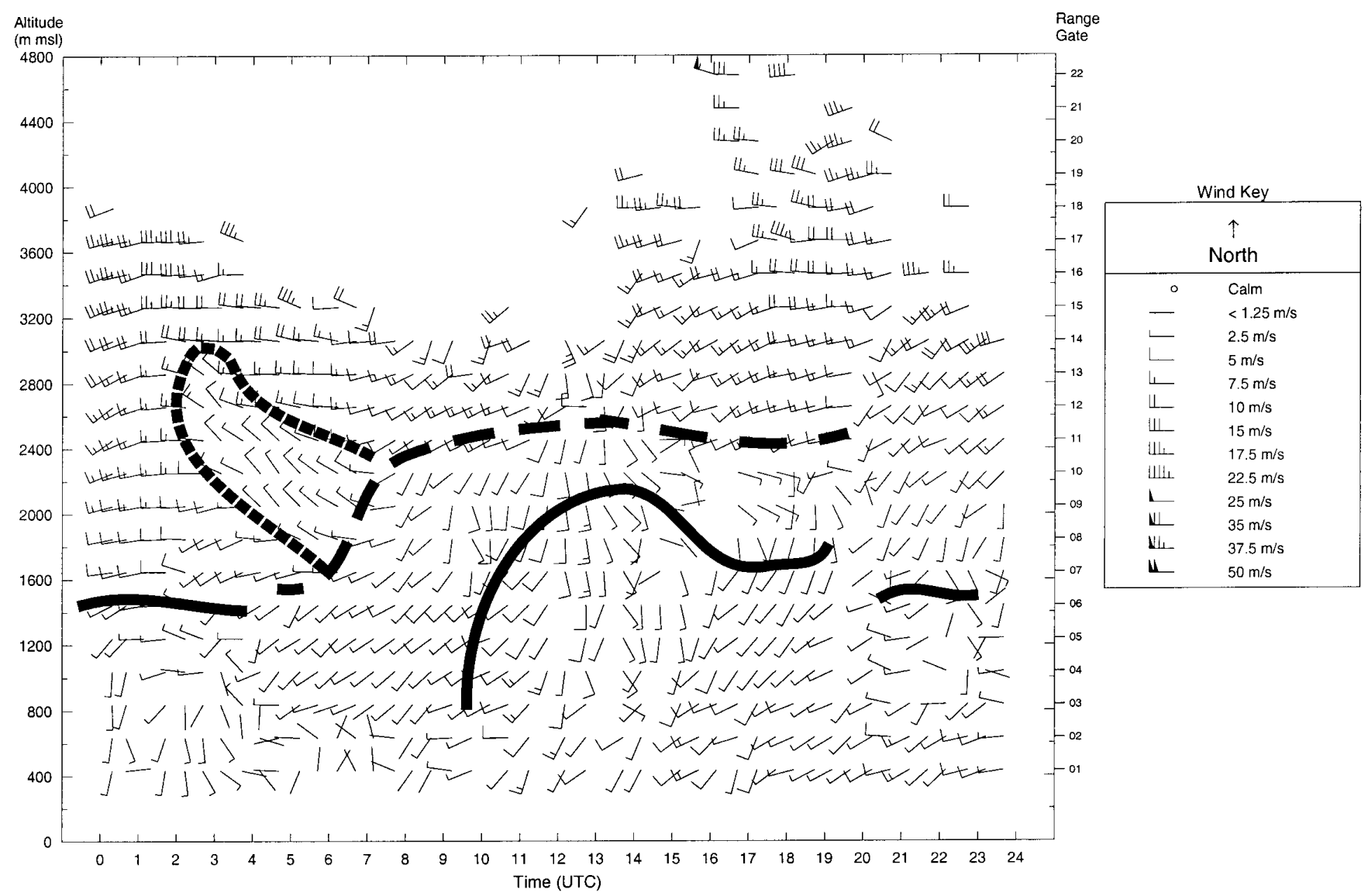

Figure 1. Wind profiler time series, Seregno, 1 June, 1998. The direction of the arrows indicates the wind direction and the number of barbs the wind speed (as mentioned in the wind key table). The solid line corresponds to the automatic determination of the characteristic height, the dashed line to the zone of strong wind shear, and the dotted line to the unexplained wind directions and speeds. 


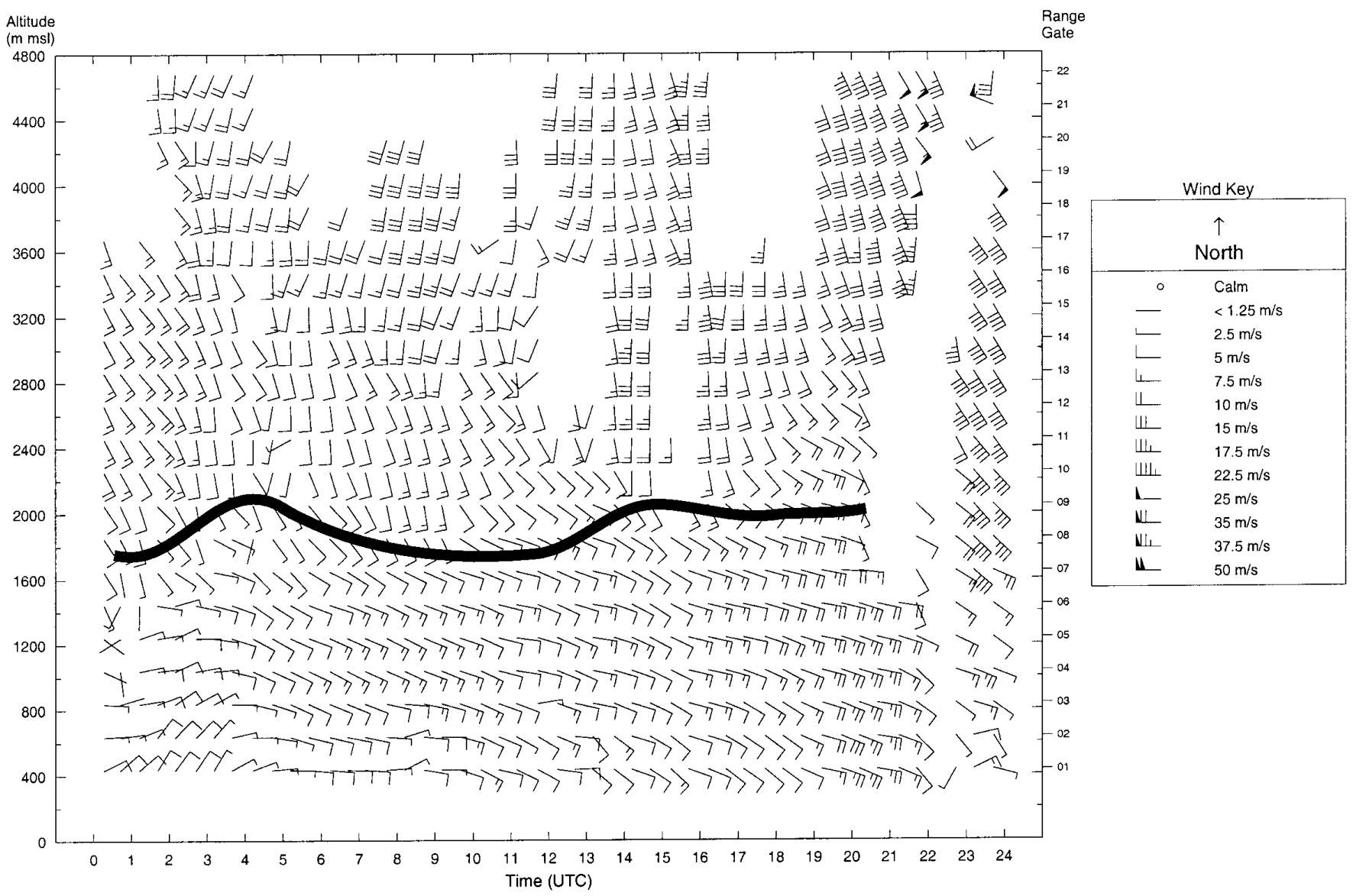

Figure 2. Same as figure 1, but for 6 June 1998.

Post-processing of the wind profiler spectra allows to automatically determine a line of maximum return signal intensity (solid lines in Fig. 1) reflecting inhomogeneities in the vertical structure of the atmosphere [2]. At nighttime, this maximum seems to correspond to the upper limit of the nocturnal stable layer; at about $10 \mathrm{~h} 00$, it can be associated with the mixing height growing quickly and reaching its maximum, $2100 \mathrm{~m}$ asl, at about 14h00. During the same day, the collocated LIDAR recorded a strong ozone increase from $13 \mathrm{~h} 00$ to $15 \mathrm{~h} 00$ [4]. Ozone profiles taken at Verzago, north of Seregno, showed a constant level of concentration (70 ppb), from ground to up to $1600 \mathrm{~m}$ asl (sounding from 18h00) [5]. Ozone concentration dropped quickly above the mixing height limit. Thus a good correspondance between the ozone profile taken at Verzago and the mixing height detected with the wind profiler can be found for that day.

The 6 June 1998, the weather was influenced by a weak cold front moving from Spain toward Italy. This perturbation produced some rain in Seregno late afternoon. The main synoptic flow was from the south. The wind profiler time series shows a simple organization of the winds during this day (Fig. 2). The southerly winds are easy to detect as well as the precipitation event in the late evening (characterized by an absence of wind data because of signal contamination). The typical diurnal evolution of the PBL is not visible. All day long, two layers separated by a well defined region of strong wind shear were observed. The automatically detected return signal maximum at about $2000 \mathrm{~m}$ asl (solid line in Fig. 2) corresponds exactly to the top of a capping inversion and to the upper limit of the very high ozone concentration measured at Verzago at $09 \mathrm{~h} 30$ and $15 \mathrm{~h} 30$ (120 ppb) [5].

\section{Conclusion}

The wind profiler is a powerful tool to describe the ventilation within the PBL as well as the interaction between the local and regional flows with the synoptic regime. The mixing height is usually determined by analyzing temperature and moisture profiles obtained by conventional sounding systems. The wind profiler is a complementary tool to detect inhomogeneities like temperature inversions and mixing 
heights in the vertical air column and to track their temporal evolution with high resolution. In the frame of LOOP, the wind profiler data will be used for analysis purposes (mainly comparisons with the collocated ozone LIDAR) as well as assimilation data in chemical and dispersion models to document the transport of pollutants.

\section{Acknowledgements}

I want to thank the SMI/Payerne crew who helped to setup the system at Seregno and the members of the EPFLLaboratoire de pollution de l'air who made it running continuously during PIPAPO.

\section{References}

1. Neff, W. D. in: Atmospheric processes over complex terrain, Blumen, W. Ed. American Meteorological Society, Boston MA, USA, 1990; No. 45; pp 173-228.

2. Jaquier, A.; Ruffieux, D.; Stübi, R. Multi-peak analysis and determination of characteristic heights with a low-tropospheric wind profiler. COST-76 Profiler Workshop, Engelberg, Switzerland, May 12-16, 1997; pp 301-304.

3. Eurotrac2-LOOP, Internet Address: http:|lwww1.psi.chl loopl.

4. Quaglia, P., Larchevêque, G.; Ancellet, G.; Jimenez, R.; Lazzarotto, B.; Simeonov, V.; Calpini, B. Planetary boundary layer ozone fluxes from combined airborne and ground based LIDARs and wind profiler, Analusis (this issue).

5. Spirig, C. Meteorologische Einflüsse auf die Ozonverteilung in der Poebene. Diploma thesis, Laboratory for Atmospheric Physics, ETH-Zurich, zurich, Switzerland, 1998, p 52. 